\title{
Contagem de células somáticas e produção leiteira em cabras Saanen estressadas via aplicação de ACTH ${ }^{1}$
}

\author{
Ana Paula Rodrigues Gaiato ${ }^{2}$, Taissa de Souza Canaes ${ }^{3}$, Thiago Ferreira Gonçalves \\ Delgado $^{3}$, Innaê Vivian Borges da Silva e Oliveira ${ }^{2}$, João Alberto Negrão ${ }^{2}$
}

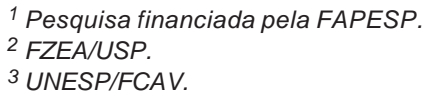

RESUMO - Avaliou-se neste estudo o efeito do estresse, via administração de ACTH (hormônio adrenocorticotrófico), sobre a quantidade e qualidade do leite produzido e a indicação de estresse pela alteração no nível de cortisol. Assim, 12 cabras lactantes foram distribuídas em dois grupos: seis animais receberam aplicação de 0,06 UI de ACTH/kg de PV (desafiadas) e seis receberam solução placebo (controle), todas via intravenosa. O desafio ocorreu ao longo da lactação, com aplicação do protocolo aos 30, 60, 120 e 180 dias do início da lactação, avaliando-se em cada data os níveis de cortisol 30 minutos antes, no ato da aplicação, 60, 120 e 300 minutos depois. A produção leiteira foi mensurada diariamente durante 270 dias e, a cada 20 dias, o leite foi colhido para contagem de células somáticas (CCS) pelo método direto. Os teores de cortisol mensurados em -30 e 0 minuto antes da aplicação de ACTH foram baixos e semelhantes entre os grupos. Entretanto, a partir de 60 minutos,

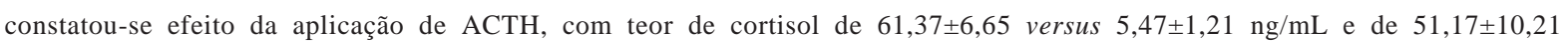

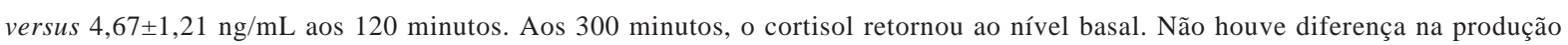

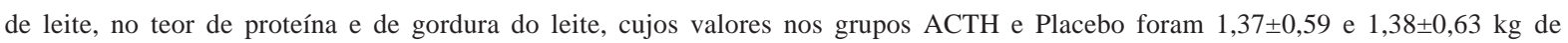
leite, respectivamente. A contagem de células somáticas não foi influenciada pelo estresse e apresentou valores situados na faixa indicada para animais sadios. Constatou-se estresse pontual em decorrência da aplicação de ACTH, porém sem alterações de natureza quantitativa e qualitativa do leite produzido, e isso indica que atividades de manejo que estressam os animais pontualmente não trazem prejuízos ao sistema produtivo.

Palavras-chave: apoptose, cortisol, leite, placebo

\section{Somatic cell count and milk production of Saanen goats stressed via application of ACTH}

\begin{abstract}
The objective of this study was to analyze the stress effect, via administration of ACTH (adrenocorticotropic hormone), on quantity and quality of milk produced and also the indication of stress by alteration of cortisol level. Twelve milking goats were divided in two groups: six animals were subjected to intravenous application of 0.06 UI of ACTH/kg of LW (challenged) and six received placebo solution (control). The challenge occurred during milking with protocol application at 30, 60, 120 and 180 days from the beginning of milking; each date the levels of cortisol were evaluated 30 minutes before, at the application of ACTH, 60, 120 and 300 minutes after ACTH. The milk production was measured daily during 270 days and every twenty days the milk was collected for somatic cell count (SCC) by the direct method. The cortisol levels measured at -30 and zero minutes before ACTH applications were low and similar between the goat groups. However, after 60 minutes it was verified the effect of ACTH application, and cortisol contents of $61.37 \pm 6.65$ versus $5.47 \pm 1.21 \mathrm{ng} / \mathrm{mL}$ and of $51.17 \pm 10.21$ versus $4.67 \pm 1.21 \mathrm{ng} / \mathrm{mL}$ at 120 minutes. At 300 minutes, the cortisol returned to basal level. There was no significant difference of milk production, protein contents and milk fat; groups ACTH and placebo produced $1.37 \pm 0.59$ and $1.38 \pm 0.63 \mathrm{~kg}$ of milk, respectively. The somatic cell count was not influenced by ACTH stress and presented values located within the range indicated for healthy animals. Punctual stress originated from ACTH application was verified, but without alterations of quantitative and qualitative nature of milk produced, indicating that management activities that punctually stress animals do not bring production impairment.
\end{abstract}

Key Words: apoptosis, cortisol, placebo, milk 


\section{Introdução}

São consideradas somáticas todas as células presentes no leite e originárias, tanto da descamação dos alvéolos apoptóticos, quanto as removidas durante o fluxo da corrente sanguínea. As principais células encontradas são os leucócitos (Paape et al., 2002; Campos et al., 2008), que são eliminados naturalmente durante o curso normal da lactação, na ordenha (Galiero, 2000; Morena, 2000).

Residentes, assim como recém-recrutados, os leucócitos mamários são constituídos por vários tipos de células, incluindo polimorfonucleares (PMNs), macrófagos e linfócitos (Sarikaya et al., 2006). Essas células mediam tanto a resposta inata quanto a resposta imune (Concha, 1986; Paape et al., 2002). Os neutrófilos (PMN) promovem reações no tecido mamário e causam distúrbios na função mamária, uma vez que geram espécies reativas de oxigênio e liberam enzimas granulares, causando grande prejuízo nas células secretoras de leite e reduzindo a produção leiteira (Paape et al., 2002).

Além das células do sistema imune, também são encontradas no leite células epiteliais relacionadas ao término da vida secretória e provenientes da descamação do tecido alveolar, presença que sugere a eliminação de células “mortas” (Boutinaud; Jammes, 2002), que variam de forma crescente do começo para o fim da lactação (Pereira et al., 2001; Coldebella et al., 2004). Neste contexto, a contagem de células somáticas no leite é um indicador da evolução e saúde da glândula mamária (Burvenich et al., 1994; Paape et al., 2002), já que, em uma glândula mamária infectada, mais de $90 \%$ das células somáticas encontradas no leite serão neutrófilos (PMN) (Boulanger et al., 2001).

O aumento na contagem de células somáticas influencia negativamente a composição do leite, a atividade enzimática, o tempo de coagulação, a produção e a qualidade dos derivados lácteos (Kitchen, 1981). O estresse aumenta as espécies reativas de oxigênio alterando os processos de divisão (hiperplasia) e morte celular (apoptose) em diferentes tecidos (Jeng Su et al., 2002). Alguns estudos também sugerem que o estresse pode intensificar o processo de apoptose na glândula mamária durante a lactação, reduzindo a produtividade dos animais (Stefanon et al., 2002; Tian et al., 2005).

Assim, objetivou-se neste trabalho estudar o estresse pontual (via administração de ACTH) sobre a contagem de células somáticas, quantidade de leite produzido, proteína e gordura do leite ao longo da lactação em cabras da raça Saanen.

\section{Materiais e Métodos}

O experimento foi conduzido no Laboratório de Fisiologia Animal, no Campus da Faculdade de Zootecnia e Engenharia de Alimentos (FZEA-USP) em Pirassununga, que apresenta clima tropical de altitude (634 $\mathrm{m}$ de altitude), localizado na latitude $22^{\circ} 00^{\prime} 00^{\prime \prime}$ sul e longitude $45^{\circ} 25^{\prime} 42^{\prime \prime}$ oeste, utilizando-se animais da raça Saanen manejados em condições de confinamento durante a lactação.

Foram utilizadas 12 cabras saudáveis compatíveis com o padrão da raça. Os animais foram alocados em baias com cobertura de telha cerâmica e piso ripado, tendo acesso a solário com piso de concreto, equivalente a mais da metade do tamanho da baia.

Como alimento volumoso, as cabras receberam silagem da planta inteira do milho e, como concentrado, receberam uma mistura de milho, farelo de soja e soja extrusada fornecido em cocho coletivo, além de sal vitamínico-mineral. Também tiveram livre acesso à água em bebedouros coletivos providos de boia. Assim, a dieta foi semelhante para todos os animais e ajustada de acordo com o AFRC (Technical Committee on Responses to Nutrients, 1997) em função da idade, do peso vivo corporal, da categoria e da produção leiteira.

A ordenha mecânica foi realizada uma vez por dia, com o equipamento regulado para manter nível de vácuo de 48 KPa e taxa de pulsação de 120 ciclos/minuto.

No início da lactação, as 12 cabras, uniformes em peso, idade e produção leiteira, foram divididas aleatoriamente em dois grupos: destas, seis foram designadas para receber via intravenosa 0,6 UI de ACTH/kg PV (Sigma, Saint Louis, Missouri, USA) (Fulkerson \& Jamieson, 1982) como desafio ao longo da lactação, iniciando a 30 dias do parto e repetido sistematicamente a 60, 120 e 180 dias do início da lactação, enquanto as outras seis cabras foram destinadas a receber, também por via intravenosa, uma solução placebo de soro fisiológico (grupo controle).

Em cada dia do desafio (administração do ACTH e/ou placebo), foi mensurado o teor de cortisol dos animais com amostras de sangue coletada diretamente da veia jugular. Cada coleta de sangue foi iniciada às $12 \mathrm{~h}$ do dia, que correspondeu a 30 minutos antes da aplicação do protocolo hormonal, sendo repetida no ato da aplicação do hormônio e novamente a 60, 120 e a 300 minutos. Esses intervalos foram padronizados até o final do experimento, conforme recomendado por Escobar et al. (1998). Também foram executadas coletas de sangue mensais para que se pudesse quantificar o cortisol basal das cabras ao longo da lactação. 
A coleta das amostras de sangue foi feita por punção da veia jugular da cabra em tubos Vacutainer ${ }^{\circledR}$ (Frankein Lakes, New Jersey, USA) heparinizados, que foram mantidos em gelo após a coleta até o início do processamento. No laboratório o sangue foi centrifugado a $3000 \mathrm{RPM}$ a $4{ }^{\circ} \mathrm{C}$ durante 17 minutos e o plasma obtido foi acondicionado em tubos e estocado a $-20{ }^{\circ} \mathrm{C}$ para posterior análise e monitoramento dos níveis de cortisol.

A determinação dos teores de cortisol foi realizada no Laboratório de Fisiologia Animal da FZEA/USP. O plasma foi descongelado e utilizado nas análises de cortisol utilizando-se kits imunoenzimáticos (Diagnostic Systems Laboratory Inc, Webster, Texas, USA). O resultado foi obtido em leitor do tipo Elisa (Multiscan MS Labsystem, Tiilitie, Vantaa, Finland), com comprimento de onda de $450 \mathrm{~nm}$, baseado em curva-padrão de 7 pontos com concentrações variando de 0,5 a $60 \mathrm{ng} / \mathrm{mL}$ de cortisol.

A produção de leite foi mensurada diariamente com ordenhadeira provida de copos coletores individuais do tipo proveta. A cada 20 dias, o leite foi colhido e submetido à contagem de células somáticas (CCS), com lâminas confeccionadas e coradas com azul de toluidina, para contagem microscópica direta (Prescott \& Breed, 1910).

Para contagem do número de células somáticas, foram observados 60 campos em cada $\mathrm{cm}^{2}$, utilizando-se microscópio óptico comum com objetiva de imersão, sendo que cada amostra foi feita em duplicata. O resultado da contagem (quantidade de células/mL de leite) de cada amostra foi obtido calculando-se a média dos campos multiplicada pelo fator do microscópio. Os dados da CCS foram transformados para Logaritmo na base 10, normalizando sua frequência de distribuição para análise estatística.

O delineamento experimental utilizado foi o inteiramente casualizado, com seis animais por grupo e o teor de cortisol foi analisado com modelo de repetibilidade em cada data de coleta ao longo da lactação. Na análise estatística da produção de leite, dos teores de gordura e de proteína e CCS, utilizou-se um modelo misto para medidas repetidas (West et al., 2007) que incluiu o efeito de tratamento (ACTH e placebo), de tempo de resposta do animal (-30, 0, 60, 120 e 360 minutos), do dia de lactação (30, 60, 120, 180 dias) e suas interações duplas. Nessas análises, utilizou-se o SAS, versão 9.2, com as médias dos efeitos principais e de interação entre fatores, comparadas pelo teste $\mathrm{F}$ em quadros de análise de variâncias. Na presença de interação significativa do tempo de resposta ou dia de lactação com o fator tratamento, optou-se pelo desdobramento da interação visando à comparação das médias dos tratamentos em cada uma das ocasiões. Adotou-se $\alpha=0,05$.

\section{Resultados e Discussão}

Ao longo da lactação, não houve efeito significativo no nível de cortisol dos animais ( $\mathrm{P}>0,05)$, independentemente de terem ou não recebido aplicação de ACTH, ou seja, em cada tempo de leitura (30 minutos antes e também no momento da aplicação do hormônio ou a 60, 120 e 300 minutos), o valor foi similar tanto dentro do grupo com ACTH quanto dentro do grupo testemunha nos quatro dias de desafio (Tabela 1).

Meia hora antes (T-30) e também no momento da aplicação dos tratamentos (ACTH ou placebo), os animais dos dois grupos avaliados apresentaram nível basal de cortisol, independentemente da data de realização da coleta ao longo da lactação $(\mathrm{P}>0,05)$. Esse comportamento continuou até 300 minutos no grupo testemunha (que receberam placebo), indicando, portanto, que o estresse decorrente apenas do processo de aplicação dos tratamentos não foi relevante.

Entretanto, houve efeito do ACTH a partir de 60 minutos após a aplicação do hormônio ( $\mathrm{P}<0,05)$, pois a concentração plasmática de cortisol do grupo desafiado foi maior que no controle, $61,37 \pm 6,65$ e 5,47 $\pm 1,21 \mathrm{ng} / \mathrm{mL}$, respectivamente.

Tabela 1 - Teores de cortisol plasmático de cabras da raça Saanen em dias de aplicação de ACTH/Placebo durante a lactação

\begin{tabular}{|c|c|c|c|c|c|c|}
\hline \multirow[b]{2}{*}{ Grupo } & \multirow[b]{2}{*}{ Dia de lactação } & \multicolumn{5}{|c|}{ Tempos de coleta de sangue (min) } \\
\hline & & -30 & 0 & 60 & 120 & 300 \\
\hline \multicolumn{7}{|c|}{ Cortisol plasmático (ng/mL) } \\
\hline \multirow[t]{4}{*}{ АСТН } & 30 & $21,3 \pm 11,1 \mathrm{aA}$ & $7,2 \pm 4,9 \mathrm{aA}$ & $68,5 \pm 11,2 \mathrm{bA}$ & $60,8 \pm 11,9 \mathrm{bA}$ & $18,9 \pm 13,6 \mathrm{aA}$ \\
\hline & 60 & $14,2 \pm 4,9 \mathrm{aA}$ & $3,8 \pm 0,3 \mathrm{aA}$ & $58,1 \pm 2,8 \mathrm{bA}$ & $52,4 \pm 2,4 \mathrm{bA}$ & $11,3 \pm 8,1 \mathrm{aA}$ \\
\hline & 120 & $3,5 \pm 1,6 \mathrm{aA}$ & $2,6 \pm 0,9 \mathrm{aA}$ & $65,1 \pm 4,1 \mathrm{bA}$ & $54,7 \pm 10,3 \mathrm{bA}$ & $8,2 \pm 7,0 \mathrm{aA}$ \\
\hline & 180 & $3,1 \pm 2,1 \mathrm{aA}$ & $1,4 \pm 0,9 \mathrm{aA}$ & $53,8 \pm 4,4 \mathrm{bA}$ & $53,2 \pm 11,7 \mathrm{bA}$ & $6,2 \pm 3,4 \mathrm{aA}$ \\
\hline \multirow[t]{4}{*}{ Placebo } & 30 & $16,1 \pm 7,3 \mathrm{aA}$ & $8,8 \pm 3,4 \mathrm{aA}$ & $6,0 \pm 3,2 \mathrm{aB}$ & $5,7 \pm 3,5 \mathrm{aB}$ & $4,3 \pm 2,4 \mathrm{aA}$ \\
\hline & 60 & $17,3 \pm 3,3 \mathrm{aA}$ & $5,7 \pm 4,9 \mathrm{aA}$ & $3,7 \pm 0,8 \mathrm{aB}$ & $3,4 \pm 0,7 \mathrm{aB}$ & $5,4 \pm 4,3 \mathrm{aA}$ \\
\hline & 120 & $11,0 \pm 6,7 \mathrm{aA}$ & $4,2 \pm 0,7 \mathrm{aA}$ & $6,3 \pm 3,5 \mathrm{aB}$ & $3,8 \pm 0,8 \mathrm{aB}$ & $10,4 \pm 9,6 \mathrm{aA}$ \\
\hline & 180 & $10,4 \pm 5,3 \mathrm{aA}$ & $3,3 \pm 0,8 \mathrm{aA}$ & $5,9 \pm 2,9 \mathrm{aB}$ & $5,7 \pm 5,0 \mathrm{aB}$ & $7,5 \pm 5,5 \mathrm{aA}$ \\
\hline
\end{tabular}

Médias seguidas por letras iguais, minúsculas na linha e maiúsculas nas colunas, não diferem entre si pelo teste Tukey a 5\% de probabilidade. 
Após 120 minutos, a concentração de cortisol foi alta no grupo desafiado $(51,17 \pm 10,21 \mathrm{ng} / \mathrm{mL})$, porém com queda acentuada, de forma que após 300 minutos da aplicação do hormônio, os valores retornaram ao nível basal, equiparando ambos os grupos. O perfil do cortisol caracterizado pelo aumento a partir de 60 minutos após a administração de ACTH, continuando com concentrações elevadas no tempo 120 e retorno ao nível basal após 300 minutos, é semelhante ao observado na literatura por Escobar et al. (1998) e Delgado (2008).

Assim, no grupo que recebeu ACTH, o valor de cortisol foi superior ao do grupo controle, destarte, houve estímulo da adrenal pelo ACTH, concordando com afirmações de Escobar et al. (1998), Negrão et al. (2004) e Delgado (2008).

Tanto o perfil quanto o aumento no nível de cortisol observado no grupo de cabras que recebeu ACTH assemelha-se ao observado após a indução de estresse por diferentes agentes, tanto em cabras (Duvaux-Ponter et al., 2003; Delgado, 2008; Canaes et al., 2009; Canaes \& Negrão, 2009) como em ovelhas (Fulkerson \& Jamieson, 1982; Marnet \& Negrão, 2000) ou vacas (Tancin et al., 1995; Rushen et al., 2001; Negrão et al., 2004; Negrão, 2008).

Na avaliação do comportamento da produção de leite ao longo da lactação, a média diária dos animais desafiados com ACTH foi igual à do grupo controle no início da

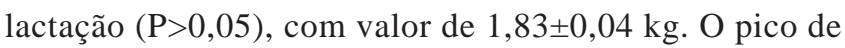
lactação ocorreu em torno de 30 dias, com produção de $2,14 \pm 0,09 \mathrm{~kg}$, porém com os animais do grupo ACTH apresentando média ligeiramente superior, mas não de forma significativa $(\mathrm{P}>0,05)$. A queda de produção persistiu com os dois grupos apresentando médias iguais a 1,08 $\pm 0,02 \mathrm{~kg}$ ao final da lactação (Figura 1). Assim, o comportamento da curva de lactação dos animais experimentais foi similar ao que se observa para a produção de cabras anglonubianas (Barros et al., 1992).

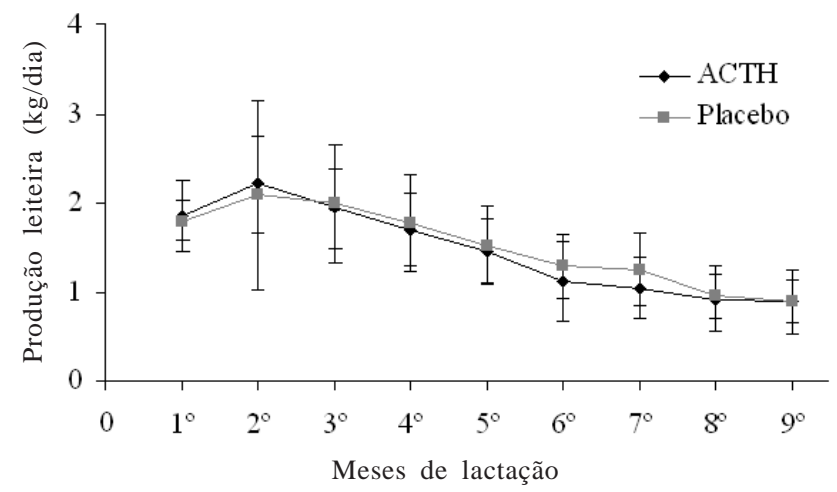

Figura 1 - Produção média de leite de cabras da raça Saanen(kg/dia) submetidas ou não a estresse via aplicação de ACTH, referentes a coletas ao longo da lactação.
Não houve diferenças na produção de leite entre os grupos $(\mathrm{P}>0,05)$, fato também verificado por Delgado (2008) em cabras Saanen tratadas com ACTH recebendo dosagem similar. Esse resultado sugere que o estresse pontual causado por manejo em situações diversas como vacinação, casqueamento e mudança de instalações não causa queda na quantidade do leite ao longo da lactação, fato que está de acordo também com resultados verificados por Fulkerson \& Jamieson(1982), Tancin etal.(1995), Marnete Negrão(2000), Rushen et al. (2001), Negrão (2008) e Porcionato et al. (2009).

Também não foram observadas diferenças nos teores de proteína (a) e gordura (b) do leite de cabras que foram estimuladas com ACTH e do grupo controle ao longo da lactação (Figura 2).

No gráfico os valores médios do teor de proteína do leite do grupo de cabras estimuladas com ACTH comportaram-se de forma similar ao do grupo testemunha. Na avaliação do comportamento médio do teor de gordura, observou-se que, na segunda coleta, o grupo testemunha apresentou média ligeiramente menor, porém não significativa $(\mathrm{P}>0,05)$. Assim, considerando que o teor de proteína e gordura do leite não diferiu entre grupos, é coerente afirmar que foi pequeno o efeito do ACTH.
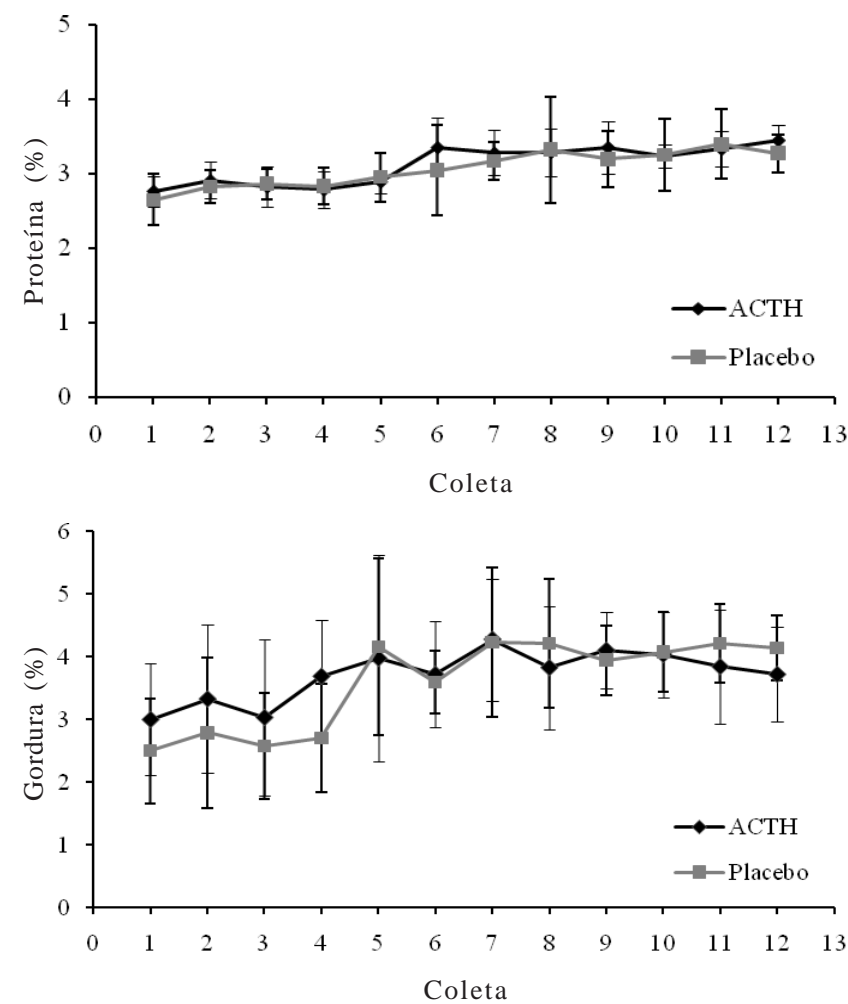

Figura 2 - Teores médios de proteína (a) e gordura (b) do leite de cabras da raça Saanen submetidas ou não a estresse via aplicação de ACTH com coletas ao longo da lactação. 
Verificou-se comportamento similar nos teores de proteína e de gordura ao longo da lactação, com tendência de elevação à medida que se aproximou do final desta. Para o teor de proteína, observou-se média de 2,7\% no início e finalizando com 3,36\%. Essa tendência também foi observada por Barbosa et al. (2002), com valores iniciais e finais de 2,30 e $4,00 \%$, respectivamente, em cabras tratadas com somatotropina para estimular a lactação. Como explicação, esses autores relacionaram o comportamento do teor de proteína ao da produção de leite ao longo da lactação, sendo que no pico de produção a concentração proteica foi menor, enquanto no final foi maior.

Similarmente ao resultado dessa pesquisa, cujos valores do teor de gordura oscilaram entre 2,75 e 4,25\%, com variação de até 1,5\%, Ramos \& Juárez (1981) também constataram oscilação entre 2,5 a 4,4\% ao longo da lactação em cabras.

Quanto à influência da aplicação de ACTH sobre a contagem de células somáticas (CCS) ao longo da lactação, constatou-se que os valores de $\log _{10}$ CCS foram semelhantes $(\mathrm{P}>0,05)$ para os grupos desafiado e controle, portanto sem influência do hormônio na contagem dessas células no leite (Figura 3).

As médias de CCS em escala natural neste trabalho $\left(1.000 \times 10^{3} \pm 300 \times 10^{3} \mathrm{cel} / \mathrm{mL}\right.$ de leite) estão na faixa apresentada na literatura de caprinos. Andrade et al. (2001) constataram em cabras de raça Alpina de alta produção médias de $1.163 \times 10^{3} \pm 962 \times 10^{3} \mathrm{cel} / \mathrm{mL}$. Segundo Paape et al. (2001), valores de 270 a $2.000 \times 10^{3} \mathrm{cel} / \mathrm{mL}$ de leite correspondem à ausência de mastite e são compatíveis com animais saudáveis.

Segundo Peters (2002), a curva da CCS numa lactação de animais saudáveis é caracterizada por elevada concentração no início, valores constantes até o meio da lactação, seguida de queda gradual até o final da lactação. Entretanto essa variação não foi observada de forma evidente nesta pesquisa, independente da aplicação do ACTH.

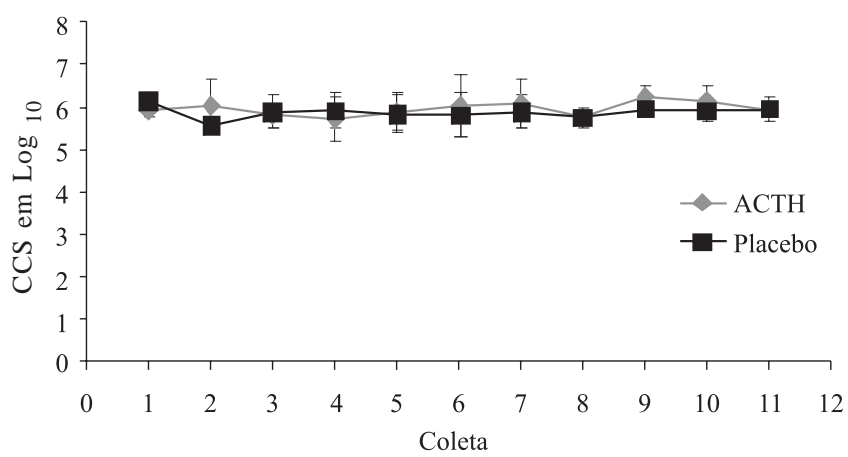

Figura 3 - $\log _{10}$ da contagem de células somáticas do leite de cabras da raça Saanen, submetidas ou não a estresse via aplicação de ACTH, com coletas ao longo da lactação.
Contrariamente ao comportamento dos teores de proteína e de gordura, verifica-se na literatura que alguns autores relacionam a diminuição da CCS à redução na produção leiteira, independentemente da espécie (Paape et al., 2001; Coldebella et al., 2004; Reksen et al., 2008). Entretanto, Peters (2002) afirmou que há correlação negativa entre a CCS e a produção de leite, ou seja, quanto maior a CCS menor a produção. Portanto, nessa pesquisa a variação observada concorda com os primeiros autores, pois a CCS variou de $1.145 \pm 495 \times 10^{3} \mathrm{cel} / \mathrm{mL}$ no início a $958 \pm 416 \times 10^{3} \mathrm{cel} / \mathrm{mL}$ no final, porém sem diferença estatística ( $\mathrm{P}>0,05)$.

Durante a lactação não houve qualquer tipo de correlação significativa $(\mathrm{P}>0,05)$ entre níveis de cortisol versus quantidade de leite e $\log _{10}$ de CCS (Tabela 2), indicando que não houve influência dos níveis de cortisol nos parâmetros observados.

É mais provável que o comportamento observado se deva à diminuição na produção leiteira ao longo da lactação, embora com a gradual involução da glândula ocorra aumento da apoptose de células alveolares e aumento da CCS (Capuco \& Akers, 1999). Todavia, como essa relação não foi observada de forma evidente nessa pesquisa, de certa forma, discorda de afirmações de que o estresse eleva a apoptose de células mamárias e diminui a produção, como afirmaram Capuco et al. (1997) e Caldoncelli et al. (2002).

Não houve efeito $(\mathrm{P}>0,05)$ da aplicação do ACTH ou do placebo nos níveis basais de cortisol (Figura 4). Pode-se

Tabela 2 - Correlações dos níveis de cortisol (basal e 60 min, equivalente ao pico de produção de cortisol) versus a produção de leite e $\log _{10}$ da CCS

\begin{tabular}{lcc}
\hline Correlação & Cortisol basal & Cortisol 60 min \\
\cline { 2 - 3 } & \multicolumn{2}{c}{$\mathrm{r}$} \\
\hline Produção de leite & $-0,06$ & 0,22 \\
$\log _{10}$ CCS & $-0,44$ & n.a. \\
\hline n.a. - Medida não analisada & &
\end{tabular}

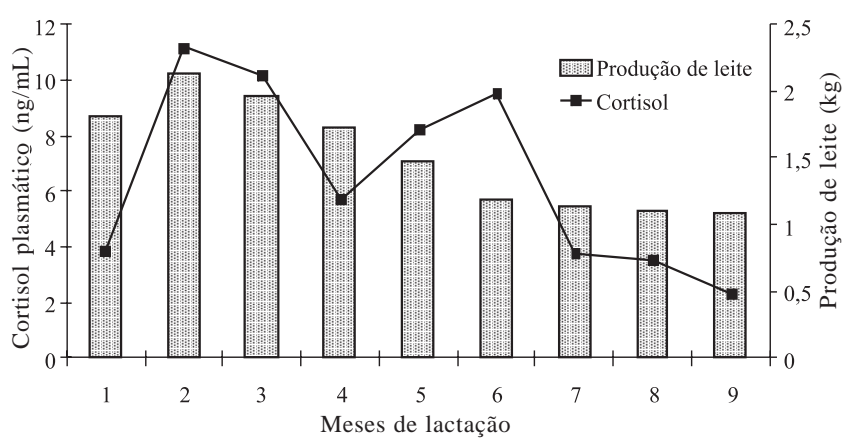

Figura 4 - Produção média de leite de cabras Saanen e concentração basal de cortisol plasmático durante a lactação. 
afirmar que não houve correlação entre níveis de cortisol e a quantidade de leite produzida, pois os coeficientes de correlação $(\mathrm{r}=-0,06)$ para o valor basal e para o valor mensurado aos 60 minutos (pico de cortisol nas cabras do grupo ACTH) $(\mathrm{r}=0,22)$ foram baixos, indicando que, mesmo tendo diminuído ao longo da lactação, a produção de leite não deve estar associada ao aumento do cortisol. A equação de regressão que melhor explica a correlação dos parâmetros observados, utilizando a concentração basal de cortisol é: Produção = 1,17 - 0,0051Cortisol, portanto, para que a quantidade de leite produzida seja diminuída em 0,1 unidade, é necessário que a concentração de cortisol aumente em 1,96 ng/mL.

\section{Conclusões}

Apesar do aumento na concentração de cortisol, que indica estresse pontual, não há diferenças na produção de leite entre grupos de cabras que recebem aplicação de ACTH e daquelas que recebem placebo. Tampouco ocorrem alterações na contagem de células somáticas, portanto manejos que estressam os animais pontualmente não trazem prejuízos produtivos ao longo da lactação.

\section{Referências}

AGRICULTURE AND FOOD RESEARCH COUNCIL - AFRC. Technical Committee on Responses to Nutrients, Report n.10. The nutrition of goats. Nutrition Abstracts and Reviews (series B), v.67, n.11, p.765-830, 1997.

ANDRADE, P.V.D.; SOUZA, M.R.; BORGES, I. et al. Contagem de células somáticas em leite de cabra. Arquivo Brasileiro de Medicina Veterinária e Zootecnia, v.53, p.396-400, 2001.

BARBOSA, P.G.; GONÇALVES, H.C.; WECHSLER, F.S. et al. Uso da somatotropina bovina recombinante - rbST como alternativa para a produção de leite de cabra na entressafra. Revista Brasileira de Zootecnia, v.31, p.2011-2023, 2002.

BARROS, N.N.; MESQUITA, R.C.M.; NETO, J.S. et al. Efeitos de níveis de energia sobre a produção de leite em cabras da raça Anglo-Nubiana. Pesquisa Agropecuária Brasileira, v.27, p.119-130, 1992.

BOULANGER, V.; BOUCHARD, L.; ZHAO, X. et al. Induction of Nitric Oxide production by bovine mammary epithelial cells and blood leukocytes. Journal of Dairy Science, v.84, p.1430-1437, 2001.

BOUTINAUD, M.; JAMMES, H. Potential uses of milk epithelial cells: a review. Reproduction, Nutrition and Development, v.42, p.133-147, 2002.

BURVENICH, C.; PAAPE, M.J.; HILL, A.W. et al. Role of the neutrophil leukocyte in the local and systemic reactions during experimentally induced $E$. coli mastitis in cows immediately after calving. Veterinary Q, v.16, p.45-50, 1994.

CALDONCELLI, F.F.; FARIAS, R.E.; GUERRA, M.O. et al. Apoptose na involução da glândula mamária. Revista Brasileira de Mastologia, v.12, p.39-44, 2002.

CAMPOS, R.; LACERDA, L.A.; TERRA, S.R. et al. Parâmetros hematológicos e níveis de cortisol plasmático em vacas leiteiras de alta produção no Sul do Brasil. Brazilian Journal of Veterinary Research and Animal Science, v.45, p.354-361, 2008 .
CANAES, T.S.; NEGRÃO, J.A. Aspectos fisiológicos, comportamentais e produtivos de cabras Alpinas submetidas ao transporte. Revista Brasileira de Zootecnia, v.38, p.893-897, 2009.

CANAES, T.S.; NEGRÃO, J.A.; PAIVA, F.A. et al. Influência do transporte e mudança do local de manejo nas variáveis fisiológicas e produtivas de cabras Alpinas. Arquivo Brasileiro de Medicina Veterinária e Zootecnia, v.61, p.935-940, 2009.

CAPUCO, A.V.; AKERS, R.M. Mammary involution in dairy animals. Journal of Mammary Gland Biology and Neoplasia, v.4, p.137-144, 1999.

CAPUCO, A.V.; AKERS, R.M., SMITH, J.J. Mammary growth in Holstein cows during the dry period: Quantification of nucleic acids and histology. Journal of Dairy Science, v.80, p.477-487, 1997.

COLDEBELlA, A.; MACHADO, P.F.; DEMÉTRIO, C.G.B. et al. Contagem de células somáticas e produção de leite em vacas Holandesas confinadas. Revista Brasileira de Zootecnia, v.33, p.623-634, 2004

CONCHA, C. Cell types and their immunological functions in bovine mammary tissues and secretions: a review of the literature. Nord Veterinary Medicine, v.38, p.257-272, 1986.

DELGADO, T.F.G. Produção leiteira em cabras da raça Saanen: influência dos hormônios cortisol e IGF-I. 2008. 91f. Dissertação (Mestrado em Zootecnia) - Faculdade de Ciências Agrárias e Veterinárias, Universidade Estadual Paulista, Jaboticabal.

DUVAUX-PONTER, C.; ROUSSEL, S.; TESSIER, J. et al. Physiological effects of repeated transport in pregnant goats and their offspring. Animal Research, v.52, p.553-566, 2003.

ESCOBAR, C.J.; BASRUR, P.K.; GARTLEY, C. et al. A comparison of the adrenal cortical response to ACTH stimulation in Angora and non-Angora goats. Veterinary Research Communications, v.22, p.119-129, 1998

FULKERSON, W.J.; JAMIESON, P.A. Pattern of cortisol release in sheep following administration of synthetic ACTH or imposition of various stressor agents. Australian Journal of Biology Science, v.35, p.215-222, 1982.

GALIERO, G.; MORENA, C. The meaning of the somatic cell count in buffalo milk. Bubalus bubalis, v.1, p.26-27, 2000.

JENG SU, W.; JU CHANG, C.; CHENG PEH, H. et al. Apoptosis and oxidative stress infiltrated neutrophils obtained from mammary glands of goats during various stages of lactation. American Journal of Veterinary Research, v.63, p.241246, 2002.

KITCHEN, B.J. Review of the progress of dairy science: Bovine mastitis: milk compositional changes and related diagnostic tests. Journal of Dairy Research, v.48, p.167-188, 1981.

MARNET, P.G.; NEGRÃO J.A. The effect of a mixed-management system on the release of oxytocin, prolactin, and cortisol in ewes during sucking and machine milking. Reproduction, Nutrition and Development, v.40, p.271-281, 2000

NEGRÃO, J.A. Hormone release and behavior during suckling and milking in Gir, Gir x Holstein cow. Journal of Animal Science, v.86, p.21-26, 2008.

NEGRÃO, J.A.; PORCIONATO, M.A.F.; PASSILLE, A.M. et al. Cortisol in saliva and plasma of cattle after ACTH administration and milking. Journal of Dairy Science, v.87, p.1713-1718, 2004.

PAAPE, M.J.; MEHZARD, J.; ZHAO, X. et al. Defense of the bovine mammary gland by polymorphonuclear neutrophil leukocytes. Journal of Mammary Gland Biological Neoplasia, v.7, p.109-121, 2002.

PAAPE, M.J.; POUTREL, B.; CONTRERAS, A. et al. Milk somatic cells and lactation in small ruminants. Journal of Dairy Science, v.84, E.Suppl., E237-E244, 2001.

PEREIRA, A.R.; MACHADO, P.F.; SARRÍES, G.A. Contagem de células somáticas e características produtivas de vacas da raça Holandesa em lactação. Scientia Agrícola, v.58, p.649-654, 2001. 
PETERS, R.R. Evaluating herd milk quality using DHI somatic cell counts. In: ARIZONA DAIRY PRODUCTION CONFERENCE, 2002, Tucson. Proceedings... Tuscon: 2002. p.57-73.

PORCIONATO, M.A.F.; NEGRÃO, J.A.; PAIVA, F.A. et al. Respostas produtivas e comportamentais durante a ordenha de vacas Holandesas em início de lactação. Acta Scientiarum, v.31, p.447-451, 2009.

PRESCOTT, S.C.; BREED. R.S. The determination of the number of body cells in milk by a direct method. American Public Health Association, v.20, p.663-664, 1910.

RAMOS, M.; JUÁREZ, M. The composition of ewe's and goat's milk. Brussels, Belgium, 1981. p.5-19. (IDF-Bulletin, 140).

REKSEN, O.; SØLVERØD, L.; ØSTERAS, O. Relationships between milk culture results and composite milk somatic cell counts in Norwegian dairy cattle. Journal of Dairy Science, v.91, p.3102-3113, 2008.

RUSHEN, J.; MUNKSGAARD, L.; MARNET, P.G. et al. Human contact and the effects of acute stress on cows at milking. Applied Animal Behaviour Science, v.73, p.1-14, 2001.
SARIKAYA, H.; SCHLAMBERGER, G.; MEYER, H.H.D. Leucocyte populations and mRNA expression of inflammatory factors in quarter milk fractions at different somatic cell score levels in dairy cows. Journal of Dairy Science, v.89, p.2479-2486, 2006.

STEFANON, B.; COLITTI, M.; GABAI, G. et al. Mammary apoptosis and lactation persistency in dairy animals. Journal of Dairy Research, v.69, p.37-52, 2002.

TANCIN, V.; HARCEK, L.; BROUCEK, J. et al. Effects of suckling during early lactation and changeover to machine milking on plasma oxytocin and cortisol levels and milking characteristics in Holstein cows. Journal of Dairy Research, v.62, p.249-256, 1995.

TIAN, S.Z.; CHANG, C.J.; CHIANG, C.C. et al. Comparison of morphology, viability, and function between blood and milk neutrophils from peak lactating goats. Canadian Journal of Veterinary Research, v.69, p.39-45, 2005.

WEST, B.T.; WELCH, K.B.; GALECKI, A.T. Linear mixed models: a practical guide using statistical software. Boca Raton: Chapman \& Hall/CRC, 2007. 339p. 